\title{
Pamukta Farklı Sulama Seviyelerinin Yaprak Su Potansiyeli ve Klorofil Değerine Etkisi
}

\section{Mine YAZDIÇ1 ${ }^{(D)}$, Hasan DEĞİRMENCİ $2^{\varnothing}$ (D)}

${ }^{1}$ DSI 12. Bölge Müdürlüğü 123. İşletme Bakım Şube Müdürlüğü, Yozgat, ${ }^{2}$ Kahramanmaraş Sütçü İmam Üniv. Ziraat Fak. Biyosistem Mühendisliği Bölümü, Kahramanmaraş

$\square:$ degirmenci@ksu.edu.tr

\section{ÖZET}

Bu çalışma, 2016 yılında Kahramanmaraş İli Doğu Akdeniz Geçit Kuşağı Araştırma Enstitüsü deneme alanında yürütülmüştür. Araştırma pamuk bitkisinde yaprak su potansiyeli ve klorofili değerini belirlemek amacıyla yapılmıştır. Deneme farklı sulama seviyelerinde $\left(\mathrm{S}_{100}, \mathrm{~S}_{75}, \mathrm{~S}_{50}, \mathrm{~S}_{0}\right) 3$ tekerrürlü olarak yürütülmüştür. Çalışma sonucuna göre $\mathrm{S}_{100}, \mathrm{~S}_{75}$, $\mathrm{S}_{50}$ ve $\mathrm{S}_{0}$ deneme konularına sırasıyla $887,654,533$ ve $0 \mathrm{~mm}$ sulama suyu uygulanmıştır. Sulama konularına göre kütlü pamuk verimleri sirasıyla 481, 406, 213 ve 106 $\mathrm{kg} \mathrm{da}^{-1} \mathrm{~d}$ r. Yaprak su potansiyeli sulama konulara göre sulama öncesi alınan ölçümler, $\mathrm{S}_{100}$ : -23.4 ile -26.91 bar, $\mathrm{S}_{75}$ : -22.74 ile -26.1 bar, $\mathrm{S}_{50}$ : 26.6 ile -31.08 bar ve sulamasız koşul So'da -33.08 ile -41.24 bar olarak ölçülmüştür. Sulama sonrasında sulama konularına $\left(\mathrm{S}_{100}, \mathrm{~S}_{75}, \mathrm{~S}_{50}, \mathrm{~S}_{0}\right)$ göre yaprak su potansiyeli değişimleri $\mathrm{S}_{100}-19.32$ ile -24.6 bar; $\mathrm{S}_{75}$ 19.6 ile -22.12 bar; $\mathrm{S}_{50}-24.65$ ile 29.12 bar; $\mathrm{S}_{0}-30.9$ ile -33.08 bar arasında ölçülmüştür. Sulama öncesi klorofil ölçüm değerleri sulama konularına göre $\mathrm{S}_{100}$ 31.8-43.5; $\mathrm{S}_{75}$ 35.4-41.6; $\mathrm{S}_{50} 40-47$; $\mathrm{S}_{0} 45.5-53.1$ arasında ölçülmüştür. Sulama sonrası klorofil değerleri ise $\mathrm{S}_{100} 35.2$ 43.9; $\mathrm{S}_{75}$ 36.1-41; $\mathrm{S}_{50} \quad 40.6-44.3 ; \mathrm{S}_{0} \quad 48.2-51.2$ arasında ölçülmüştür. Sulama konuları dikkate alındığında yaprak su potansiyeli ve klorofil değerinin su stresini belirlemede ve sulama programlanmasinda kullanılabileceği söylenebilir.

\section{DOI:10.18016/ ksudobil.369337}

Makale Tarihçesi

Geliş Tarihi : 21.12.2017

Kabul tarihi : 05.03.2018

\section{Anahtar Kelimeler}

Pamuk,

Yaprak su potansiyeli,

Klorofil değeri,

Kısıntılı sulama

\section{Araştırma Makalesi}

\section{Effect on Leaf Water Potential and Chlorophyll Value of Different Irrigation Levels in Cotton}

\section{ABSTRACT}

This study was carried out during the cotton growing season in Kahramanmaraş Province at Eastern Mediterranean Crossing Belt Research Institute trial site in 2016. This research was conducted to determine leaf water potential and chlorophyll value in cotton: Different irrigation levels $\left(\mathrm{S}_{100}, \mathrm{~S}_{75}, \mathrm{~S}_{50}, \mathrm{~S}_{0}\right)$ was applied with three replications. In current study 887, 654, 533 and $0 \mathrm{~mm}$ irrigation water was given to test subjects of $\mathrm{S}_{100}, \mathrm{~S}_{75}, \mathrm{~S}_{50}$ and $\mathrm{S}_{0}$, respectively. According to test subjects in turn, mean seed cotton yield was 481, 406, 213 and $106 \mathrm{~kg} \mathrm{da}^{-1}$; leaf water potential ranged between -19.32 and -24.60 bar in $\mathrm{S}_{100},-19.60$ and -22.12 bar in $\mathrm{S}_{75},-24.65$ and 29.12 bar in $\mathrm{S}_{50},-30.90$ and -33.08 bar in $\mathrm{S}_{0}$. Leaf chlorophyll value prior to irrigation was measured as $31.80-43.50$ in $\mathrm{S}_{100}, 35.40-41.60$ in $\mathrm{S}_{75}$, 40.60-43.30 in $\mathrm{S}_{50}, 48.20-51.20$ in $\mathrm{S}_{0}$. Consequently, leaf water potential and chlorophyll content can be used to determine water stress and use for irrigation scheduling.

\section{Article History}

Received : 21.12.2017

Accepted : 05.03.2018

\section{Keywords \\ Cotton, \\ Leaf water potential, \\ Chlorophyll value, \\ Deficit irrigation}

\section{Research Article}

To Cite : Yazdıç M, Değirmenci H 2018. Pamukta Farklı Sulama Seviyelerinin Yaprak Su Potansiyeli ve Klorofil Değerine Etkisi. KSÜ Tarim ve Doğa Derg 21(4):511-519, 2018. DOI:10.18016/ ksudobil.369337

\section{GİRIŞ}

Yaprak su potansiyeli, bitkinin içsel durumunu tanımlayan ve kolaylıkla ölçülebilen bir parametredir. Son yıllarda teknolojideki gelişmelere paralel olarak, yüksek gelir sağlayan ürünlerin sulama programlamasında yaygin olarak kullanılmaya başlanmıştır. Bu yöntem, suyu daha randımanlı ve yüksek üniformite ile uygulayabilen mikro-sulama 
(damla, mini-sprink gibi) yöntemleri ile birlikte kullanıldığında sulama suyundan önemli düzeyde tasarruf sağlanmakta ve su kullanım randımanı da en üst düzeye çıkmaktadır. (Çolak ve Yazar, 2012). Pamuk bitkisi yaprak su potansiyelinin belirlenmesine yönelik farklı ülke ve bölgelerde çeşitli araştırmacılar çalışmalar yapmışlardır. Wanjura ve Upchurch (2002) mısır ve pamuk bitkisi üzerine yapmış oldukları bir çalışmada yaprak su potansiyeli her iki bitki için sulamanın azalması ile düşüşler göstermiştir. Bu da yaprak su potansiyelinin sulama konusunda değişime duyarlı olduğunu göstermiştir. Pamuk sulama zaman planlamasında, yaprak su potansiyeli -17.8 bar değerinin kullanılabileceğini belirlemiştir. Argyrokastritisa ve ark. (2015) Akdeniz koşullarında yaptıkları pamuk denemesinde yaprak su potansiyelini 2006 yllinda -2.18 ile $-2.31 \mathrm{MPa}$ arasinda, 2007 yllinda ise -2.22 ile $-2.41 \mathrm{MPa}$ arasinda belirlemişlerdir.

Bitkilerin gelişebilmesi için fotosentez yapmaları gerekmektedir. Pamuk bitkisinde kalite ve verim için fotosentez kaçınılmaz bir olaydır. Yüksek klorofil içeriğine sahip genotiplerden daha yüksek ürün verimi elde edilir. $\mathrm{Bu}$ amaçla pamuk bitkisinde klorofil içeriğine bitki verimi ve kalite parametrelerini nasıl etkilediğini belirlemek amacıyla klorofil içeriği ölçülmektedir. Pamuk bitkisi bir çok bitkide olduğu gibi yapraklarında, fotosentez işlemi sırasında işık enerjisini kimyasal enerjiye dönüştürebilmek için klorofil pigmentlerine ihtiyaç duymaktadır (Judith ve Kenji, 1990). Yaprak klorofil içeriğini belirlemede kullanılan geleneksel yöntemler zaman alıcı ve zahmetli olduğu için klorofilmetre (SPAD) cihazı gibi yapraktaki nisbi klorofil içeriğini hızlı ve kolay bir biçimde ölçebilen cihazlar kullanılmaktadır (Li ve ark., 2014). Ekinci ve ark. (2008) yaprak klorofil değerinin yaprak şekline bağlı olmadan daha çok genetik yapısına bağlı olarak değişim gösterdiğini belirlemişlerdir. Burke ve Mahony (2001) $25^{0} \mathrm{C}$ 'nin altında ve $30^{\circ} \mathrm{C}$ 'nin üzerindeki sicaklıklarda klorofil birikiminin önemli seviyede azaldığını belirlemişlerdir. Karademir ve ark. (2009) 20 farklı pamuk genotipinde kuraklık stresi koşullarında klorofil içeriğinin verim üzerine önemli etkisinin olduğunu ve klorofil değerini ise 30.20-42.93 arasinda belirlemişlerdir. Patil ve ark. (2011) azalan sulama suyu miktarı ile pamuk yapraklarında klorofil içeriğinin önemli derecede arttığını belirlemişlerdir. Güreli ve Mert (2016) Diyarbakır koşullarında pamuk genotiplerinin klorofil değerini 2013 yılında 47.0, 2014 yılında ise 49.0 olarak bulmuşlardır.

$\mathrm{Bu}$ çalışmanın amacı, farklı sulama seviyelerinde pamuk bitkisinde sulama öncesi ve sonrası yaprak su potansiyeli ve klorofil değerinin zaman boyutunda değişiminin belirlenmesi ve sulama zamanının belirlenmesinde yaprak su potansiyeli (YSP) değerlerinden yararlanma olanaklarının araştırılmasıdır.

\section{MATERYAL ve METOT}

Araştırma Kahramanmaraş Doğu Akdeniz Geçit Kuşağı Tarımsal Araştırma Enstitüsünde (DAGTEM) yürütülmüştür. Çalışmanın yürütüldüğü deneme alanındaki toprağın tarla kapasitesi \%26.34-\%23.07 ve solma noktası \%13.22-\%14.81 arasında değişmektedir. $\mathrm{Bu}$ verilere göre $90 \mathrm{~cm}$ profil derinliğindeki kullanılabilir su miktarı $126.0 \mathrm{~mm}$ olarak hesaplanmıştır. Katmanlara göre hacim ağırlığı 1.43$1.46 \mathrm{~g} \mathrm{~cm}^{-3}$ arasinda bulunmuştur. Deneme alanı toprakları $0-30 \mathrm{~cm}$ ve $30-60 \mathrm{~cm}$ katmanları arasinda killi-tın ve $60-90 \mathrm{~cm}$ katmanında ise kumlu-killi tın olduğu belirlenmiştir. Denemenin yürütüldüğü bölge tipik Akdeniz iklimi olup kışları ılık ve yağışlı, yazlar sıcak ve kuraktır. Denemenin yapıldığ 1 bölgede pamuğun vejetasyon dönemine ait 2016 yılı iklim verileri Çizelge 1'de verilmiştir.

Çizelge 1. Deneme alanında 2016 yll ortalama iklim verileri

\begin{tabular}{lcccccc}
\hline \multicolumn{1}{c}{ Aylar } & $\begin{array}{c}\text { Max. sıcaklık } \\
\left({ }^{\circ} \mathrm{C}\right)\end{array}$ & $\begin{array}{c}\text { Min. sicaklık } \\
\left({ }^{\circ} \mathrm{C}\right)\end{array}$ & $\begin{array}{c}\text { Ort. sicaklık } \\
\left({ }^{\circ} \mathrm{C}\right)\end{array}$ & $\begin{array}{c}\text { Toplam } \\
\text { yağ } 1 \text { }(\mathrm{mm})\end{array}$ & $\begin{array}{c}\text { Oransal nem } \\
(\%)\end{array}$ & $\begin{array}{c}\text { Rüzgâr hızı }(\mathrm{m} \mathrm{s} \\
1)\end{array}$ \\
\hline Nisan & 30.8 & 8.6 & 18.8 & 17.6 & 41.2 & 1.32 \\
Mayıs & 35.5 & 9.7 & 21.8 & 18.7 & 47.9 & 1.70 \\
Haziran & 41.3 & 14 & 26.8 & 17.9 & 40.3 & 1.92 \\
Temmuz & 42 & 19.8 & 29.7 & 1.0 & 36.5 & 2.1 \\
Ağustos & 42.8 & 21.4 & 30.7 & 1.0 & 40.9 & 1.86 \\
Eylül & 38.7 & 11.3 & 24.9 & 23.7 & 39.2 & 1.68 \\
Ekim & 32.5 & 9.2 & 19.3 & 10.7 & 38.9 & 1.05 \\
\hline
\end{tabular}

Denemede kullanılan sulama suyu sinıfi $\mathrm{C}_{2} \mathrm{~S}_{1}$ olup sulamaya uygundur. Çalışmada bölgenin standart çeşitlerinden olan Stoneville 468 (Gossypium hirsutum L.) pamuk çeşidi kullanılmıştır. Sulama uygulamalarında verilecek sulama suyu miktarı Class A pan buharlaşma kabından sulama aralığına bağlı olarak buharlaşan yığışımlı su miktarları dikkate alınarak belirlenmiştir. Çalışma 4 sulama konusu $\left(\mathrm{S}_{100}\right.$, $\left.\mathrm{S}_{75}, \mathrm{~S}_{50}, \mathrm{~S}_{0}\right)$ ve 3 tekerrür olmak üzere tesadüf parseller deneme desenine göre planlanmiştır. Konulu sulamalara geçmeden önce $\mathrm{S}_{0}$ konusu hariç diğer tüm konulara $207 \mathrm{~mm}$ su verilmiştir. Konulu sulamalara 28 Haziran 2016 tarihinde başlanılmıştır. Deneme sezonu 
boyunca 12 sulama uygulanmıştır. S S100 konusu, 0-90 cm kök bölgesindeki kullanılabilir nemin tüketilen kısmın tamaminin; $\mathrm{S}_{75}$ konusu, $\mathrm{S}_{100}$ 'e uygulanan suyun \% 75'inin; $\mathrm{S}_{50}$ konusu, $\mathrm{S}_{100}$ 'e uygulanan suyun \% 50'ının;
So konusuna ise, bir kez can suyu uygulanmış ve gelişme dönemi boyunca sulama yapılmamıştır (Şekil 1.)

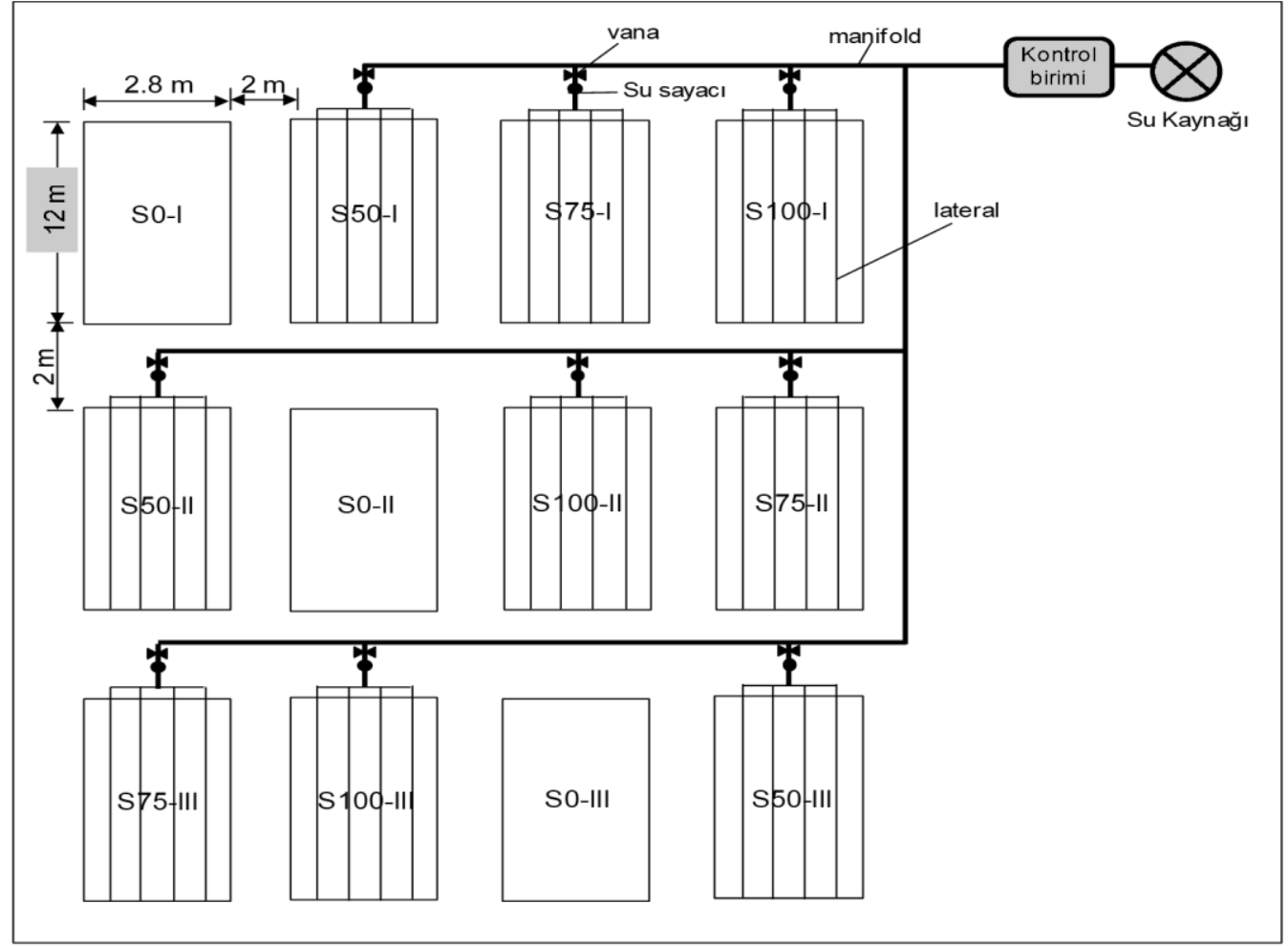

Şekil 1. Sulama konularının tesadüf blokları deneme desenine göre dağılımı

Pamuk bitkisinin 23 Nisan'da ekimi yapılmış 29 Eylül ve 29 Ekim tarihlerinde de birinci ve ikinci hasatları yapılmıştır. Bitkinin ekimi sıra arası $70 \mathrm{~cm}$, sıra üzeri $20 \mathrm{~cm}$ olacak şekilde mibzerle yapılmıştır. Denemenin sulanmasında damla sulama yöntemi kullanılmıştır. Damla sulama borularının çapı $16 \mathrm{~mm}$, damlatıcı aralıkları $40 \mathrm{~cm}$, damlatıcı debisi $4 \mathrm{~L} \mathrm{~h}^{-1}$ ve damlatıcı tipi içten geçik (in-line) olarak seçilmiştir. Tohum ekimi öncesi dekara saf olarak $6 \mathrm{~kg} \mathrm{~N}, 6 \mathrm{~kg} \mathrm{P}_{2} \mathrm{O}_{5}$ ve $6 \mathrm{~kg} \mathrm{~K} 2 \mathrm{O}$ 15-15-15 gübresi uygulanmıştır. Ayrıca dekara $3 \mathrm{~kg}$ taraklanma döneminde ve $3 \mathrm{~kg}$ çiçeklenme döneminde olmak üzere toplam $6 \mathrm{~kg}$ saf azot sulama suyuyla birlikte verilmiştir. Pamuk kozalarının \%10'u açılınca sulama işlemine son verilmiştir.

\section{Yaprak Su Potansiyeli Ölçümü}

Farklı sulama seviyelerinde pamuk bitkisinin dijital yaprak su potansiyeli cihazı (basınç odacığı aleti) ile ölçülmüştür (Baştuğ ve Kanber, 1989). Ölçümler, sulama konularına $\left(\mathbf{S}_{100}, \mathbf{S}_{75}, \mathbf{S}_{50}, \mathbf{S}_{0}\right)$ göre sulamalardan önce ve sonra olmak üzere 12:00-13:00 saatleri arasında yapılmıştır. Ölçümlerde, pamuk bitkisinin en üstte ve güneşe bakan 3 yaprakta ölçüm yapılmıştır. Buna göre alınan verilerin ortalaması ile yaprak su potansiyeli değeri belirlenmiştir. Yaprak su potansiyeli ölçümü için yapraklar bitki gövdesinden kesilmiş, yaprak sapının ucu dışarı çıkacak şekilde cihazın basınç odacı̆̆ına koyulmuştur. Yaprak ayası üzerine basınç uygulanarak sapın dışarıda kalan ucunda su damlası çıkıncaya dek basınç artırılmıştır. Yaprak sapı ucunda su kabarcığı belirdiği andaki değer yaprak su potansiyeli değeri olarak kaydedilmiştir (Hisio, 1993).

\section{Klorofil Değeri}

Klorofil ölçümleri bitki yetişme periyodu boyunca sulama öncesi ve sonrası olmak üzere tüm konularda referans belirlenen bitki ve yapraklarda taşınabilir klorofilmetre (Minolta SPAD-502) cihaziyla yapılmıştır (Fischer, 2001). Ölçümler sulama konularına göre havanın bulutlu olmadığı günlerde ve güneş ışınlarının geliş açısının en az değiştiği saat 10:00 ile 14:00 arasında gerçekleşmiştir.

\section{İstatistiksel Analizler}

Denemede her bir özellik için elde edilen veriler tesadüf parselleri deneme desenine göre analiz edilmiştir. Ortalamaların karşılaştırılmasında SPSS istatistik paket programı kullanılmış ve Duncan testi uygulanmıştır.

\section{BULGULAR ve TARTIŞMA}

Bitki Su Tüketimi ve Sulama Suyu Miktarı 
Araştırmada sulama konularına göre 2016 yilında verilen sulama suyu miktarı ve bitki su tüketimleri Çizelge 2'de verilmiştir. Çalışmada $\mathrm{S}_{100}$ konusuna toplam $887 \mathrm{~mm}, \mathrm{~S}_{75}$ konusuna toplam $654 \mathrm{~mm}$ ve $\mathrm{S}_{50}$ konusuna toplam $533 \mathrm{~mm}$ sulama suyu uygulanmıştır. $\mathrm{S}_{0}$ (sulamasız) konuya sulama suyu uygulaması yapılmamıştır. En yüksek bitki su tüketimi topraktaki eksik nemin tam olarak karşılandığı $\mathrm{S}_{100}$ konusundan elde edilirken en düşük bitki su tüketimi ise $\% 0$ kısıntı yapılan konudan elde edilmiştir. Sulama konularına $\left(\mathrm{S}_{100}, \mathrm{~S}_{75}, \mathrm{~S}_{50}, \mathrm{~S}_{0}\right)$ göre mevsimlik su tüketimleri sirasiyla 1019, 801, 707 ve $151 \mathrm{~mm}$ olarak bulunmuştur.

Çizelge 2. Denemede uygulanan toplam sulama suyu miktarı ve bitki su tüketimi değerleri

\begin{tabular}{ccccccc}
\hline Konular & $\begin{array}{c}\text { Toplam sulama } \\
\text { suyu miktarı }(\mathrm{mm})\end{array}$ & $\begin{array}{c}\text { Toplam } \\
\text { Yağış }(\mathrm{mm})\end{array}$ & $\begin{array}{c}\text { Ekimdeki } \\
\text { nem }(\mathrm{mm})\end{array}$ & $\begin{array}{c}\text { Hasattaki nem } \\
(\mathrm{mm})\end{array}$ & $\Delta \mathrm{S}(\mathrm{mm})$ & ET $(\mathrm{mm})$ \\
\hline $\mathrm{S}_{100}$ & 887 & 88.4 & 204.1 & 160.5 & 43.6 & 1019 \\
$\mathrm{~S}_{75}$ & 654 & 88.4 & 204.1 & 145.3 & 58.9 & 801 \\
$\mathrm{~S}_{50}$ & 533 & 88.4 & 204.1 & 118.4 & 85.7 & 707 \\
$\mathrm{~S}_{0}$ (sulamasız) & 0 & 88.4 & 204.1 & 141.5 & 62.7 & 151 \\
\hline
\end{tabular}

Ertek ve Kanber (2001) pamuk denemesinde 322 - 472 mm sulama suyu uygulamışlar, mevsimlik su tüketimi miktarları ise 449-615 mm olarak tespit etmişlerdir. Maya (2007)'de yaptığ sulama konularını açık su yüzeyi buharlaşma kabında (class A pan) elde ettiği sonuçlara göre 493-163 mm sulama suyu uygulamış ve mevsimlik su tüketimini 675-358 mm olarak bulmuştur.

\section{Yaprak Su Potansiyeli Ölçümleri}

Yaprak su potansiyelinin ölçümü bitkinin sulama zamanını gösteren bir parametredir. Yaprak su potansiyeli (YSP) ölçümlerine ilk koza çatlamasından sonra yani 9 . sulama yapılmadan önce başlanmış (8 Ağustos), konulu sulama bitince (25 Ağustosa) son verilmiştir. Bu dönem içinde sulama öncesi ve sulama sonrası 4 defa tekrarlanmıştır. Sulama konularına göre sulama öncesi ve sonrası ölçülen yaprak su potansiyeli sonuçları Şekil 2 ve 3'de verilmiştir.

Sulama öncesinde sulama konularına $\left(\mathrm{S}_{100}, \mathrm{~S}_{75}, \mathrm{~S}_{50}, \mathrm{~S}_{0}\right)$ göre yaprak su potansiyeli değişimleri $\mathrm{S}_{100}$-23.4 ile 26.91 bar; $\mathrm{S}_{75}-22.74$ ile -26.1 bar; $\mathrm{S}_{50}-26.6$ ile -31.08 bar; $\mathrm{S}_{0}-33.08$ ile -41.24 bar arasında değişmektedir. Sulama öncesinde ölçülen değerlerde düşme eğilimi (daha büyük negatif sayılar) görülmüsstür. Sulama sonrasinda sulama konularına $\left(\mathbf{S}_{100}, \mathbf{S}_{75}, \mathbf{S}_{50}, \mathbf{S}_{0}\right)$ göre yaprak su potansiyeli değişimleri $\mathrm{S}_{100}-19.32$ ile -24.6 bar; $\mathrm{S}_{75}-19.6$ ile -22.12 bar; $\mathrm{S}_{50}-24.65$ ile 29.12 bar; $\mathrm{S}_{0}$ -30.9 ile -33.08 bar arasında değişmektedir. Sulama sonrası ölçülen değerlerin genel olarak yükseldiği (daha küçük negatif sayılar) görülmüştür.

Maya (2007) yapmış olduğu pamuk denemesinde sulama öncesi YSP değerleri incelendiğinde genellikle tam sulamanın yapıldığı I1 (\%100) konusunda -15.5 bar, I2 (\%70)'de - 16 ile-18 bar ve I3 (\%50)'de ise -22 ile23 bar'da sulama yapıldığını belirtmiştir. Bulunan değerler, pamukta sulama planlanmasinda oluşturulacak su stres seviyelerine göre sulamaya başlamak için birer indeks noktası olarak kabul edilebileceğini belirtmiştir. Wanjura ve Upchurch (2002) bitki su stresine göre yapmış oldukları pamuk denemesinde yaprak su potansiyeli değerinde sulamanın azalması ile düşüşler görüldüğünü ve sulama konusunda değişime duyarlı olduğunu belirlemişlerdir.

\section{Yaprak Su Potansiyeli (YSP) - Bitki Su Tüketiminin (ET) İlişkisi}

Sulama konularına göre $\left(\mathrm{S}_{100}, \mathrm{~S}_{75}, \mathrm{~S}_{50}, \mathrm{~S}_{0}\right)$ ortalama yaprak su potansiyeli ile bitki su tüketimi arasındaki Duncan gruplama ilişkisi Çizelge 3'de verilmiştir. Çizelge 3’de görüldüğü gibi sulama öncesi ve sonrası yaprak su potansiyeli (YSP) ortalama değerlerinde negatif yönde en düşük $S_{75}$ konusunda iken en yüksek $\mathrm{S}_{0}$ konusunda görülmüştür. Bitkiye ilişkin yaprak su potansiyeli (YSP) değeri ile bitki su tüketimi (ET) arasında ilişkiler zıt yönde çıkmıştır. Buna göre genel olarak yaprak su potansiyeli değerinde negatif yönde artış oldukça bitki su tüketim değerinde azalma olmuştur. Bunun nedeni topraktaki nem miktarından kaynaklanmaktadir.

Sulama öncesi ve sonrası ortalama yaprak su potansiyeli ile bitki su tüketimi arasındaki ilişki Şekil 4'de verilmiştir. Sulama konularına göre yaprak su potansiyeli ile bitki su tüketimi arasında doğrusal bir ilişki bulunmuştur. Alınan değerlere ilişkin denklemler sulama öncesi $0.0146 x^{-} 38.293\left(\mathrm{R}^{2}=\right.$ $0.9195)$, sulama sonrasi $\mathrm{y}=0.0118 \mathrm{x}^{-33.248}\left(\mathrm{R}^{2}=\right.$ 0.8334 ) bulunmuştur. 


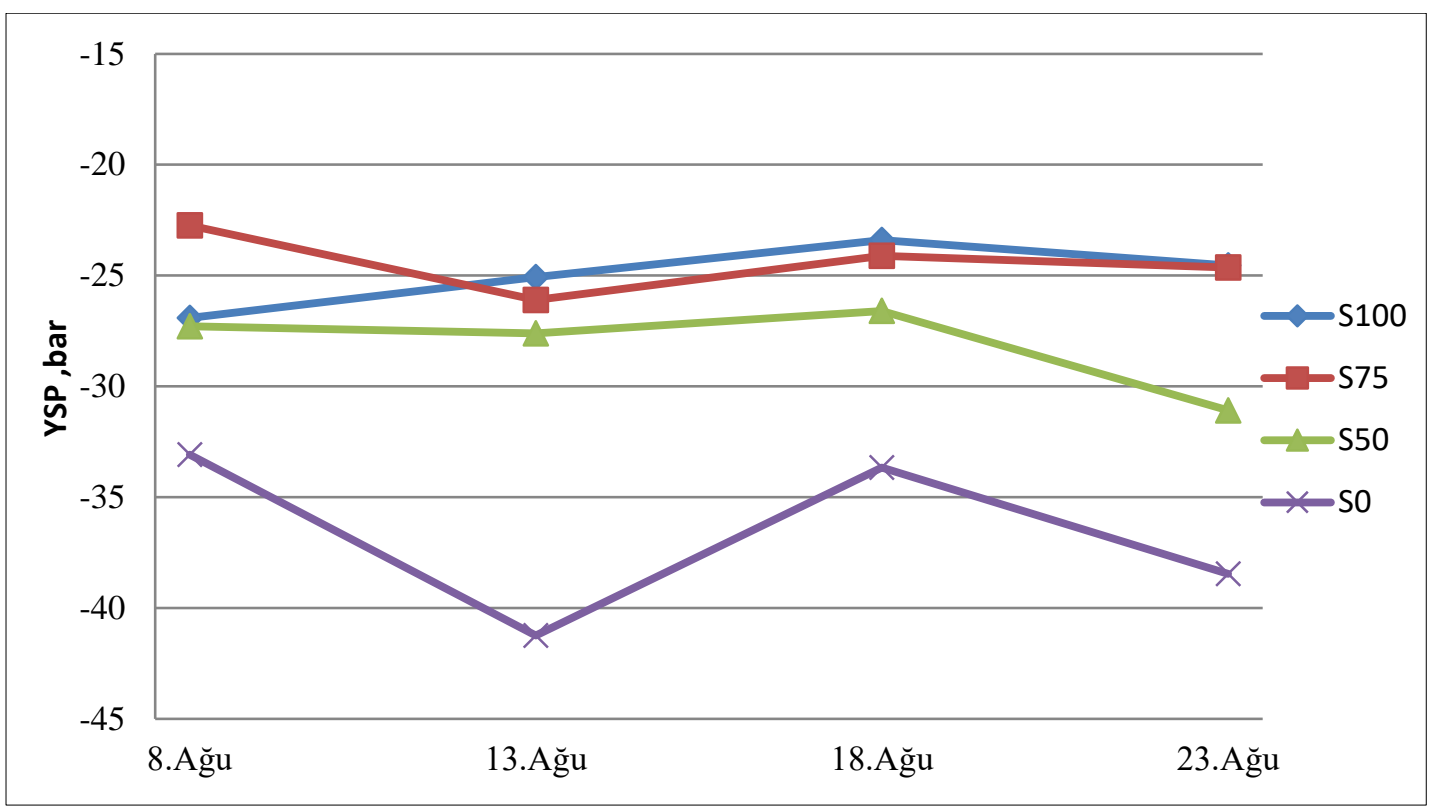

Şekil 2. Sulama öncesi yaprak su potansiyeli ölçümleri

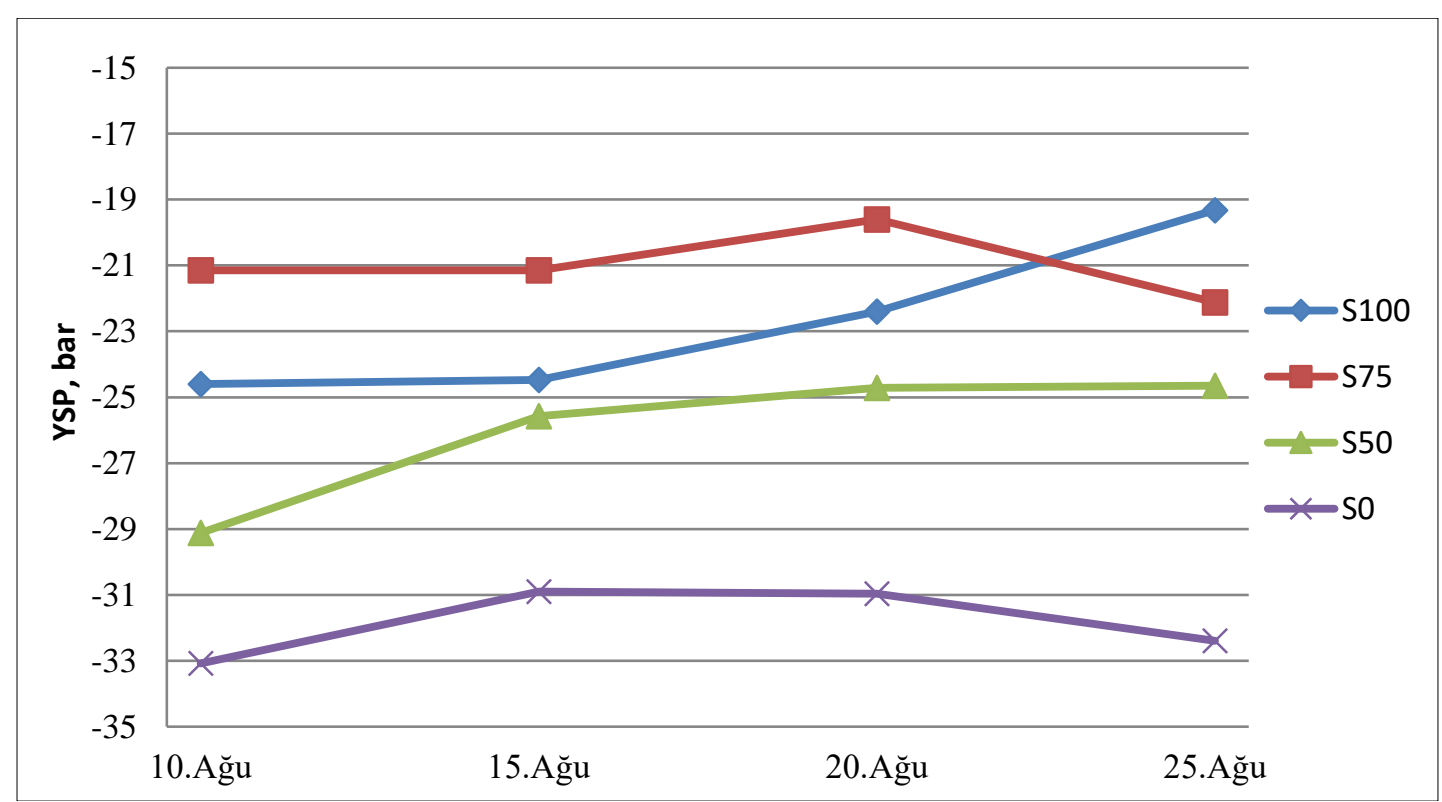

Şekil 3. Sulama sonrası yaprak su potansiyeli ölçümleri

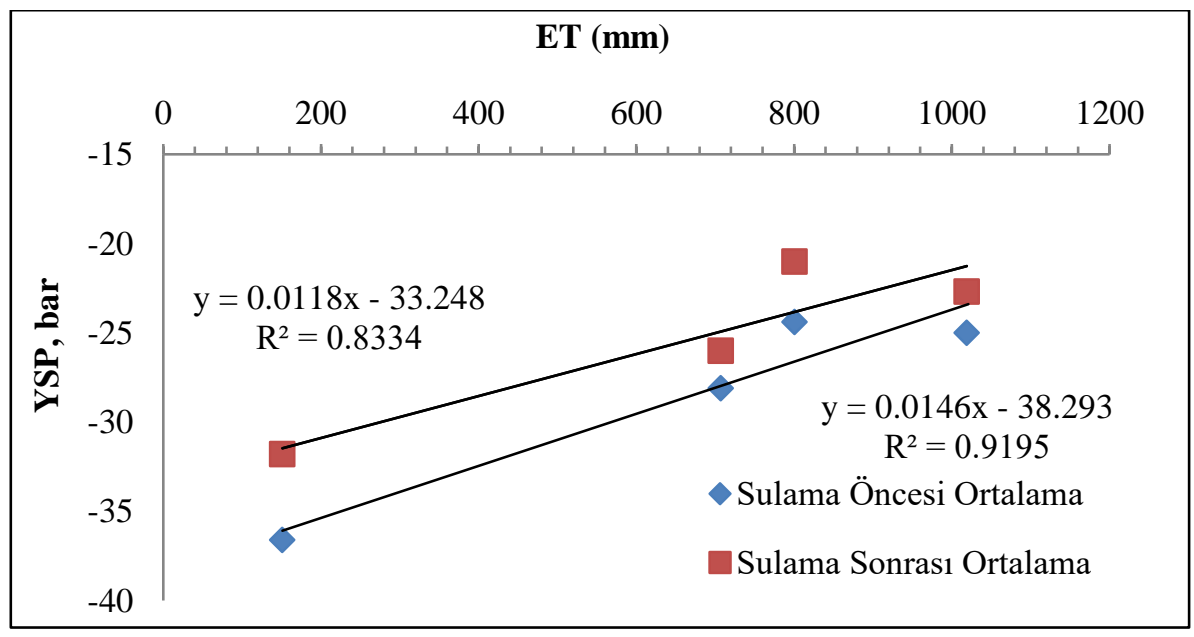

Şekil 4. Yaprak su potansiyeli - bitki su tüketim ilişkisi 
Çizelge 3. Yaprak su potansiyeli bitki su tüketim Duncan gruplama ilişkisi

\begin{tabular}{cccc}
\hline Sulama Konular1 & $\begin{array}{c}\text { ET } \\
(\mathrm{mm})\end{array}$ & $\begin{array}{c}\text { YSP Sulama Öncesi } \\
\text { Ortalama (bar) }\end{array}$ & $\begin{array}{c}\text { YSP Sulama Sonras1 } \\
\text { Ortalama (bar) }\end{array}$ \\
\hline $\mathrm{S}_{100}$ & 1018.98 & $-25.0 \mathrm{~b}$ & $-22.7 \mathrm{~b}$ \\
$\mathrm{~S}_{75}$ & 800.77 & $-24.4 \mathrm{a}$ & $-21 \mathrm{a}$ \\
$\mathrm{S}_{50}$ & 707.04 & $-28.1 \mathrm{c}$ & $-26 \mathrm{c}$ \\
$\mathrm{S}_{0}$ & 151.06 & $-36.6 \mathrm{~d}$ & $-31.8 \mathrm{~d}$ \\
\hline
\end{tabular}

\section{Klorofil Değeri (SPAD)}

Sulama konularına $\left(\mathrm{S}_{100}, \mathrm{~S}_{75}, \mathrm{~S}_{50}, \mathrm{~S}_{0}\right)$ göre çiçeklenme döneminden sonra sulama öncesi ve sonrası olmak üzere klorofil değerleri ölçülmüştür. Klorofil ölçümleri koza oluşumu olan 13 Temmuz 2016 ile son sulama dönemi olan 25 Ağustos 2016 tarihleri arasında yapılmıştır. Sulama öncesi ve sonrası ölçülen ortalama klorofil değerleri ve Duncan gruplandırması sonuçları Çizelge 4 ve 5'de verilmiştir.
Sulama öncesi klorofil değerleri Duncan testi sonuçlarına göre sulamalar arasında \%5 önem düzeyinde istatistiksel farklılıklar bulunduğu belirlenmiştir. En yüksek değer sulanmayan konuda $\mathrm{S}_{0}$ elde edilirken en düşük $\mathrm{S}_{75}$ konusunda olduğu görülmüştür. Sulama öncesi Duncan sınıflandırmasına göre klorofil değerleri yüksek çıkmıştır (Çizelge 4).

Çizelge 4. Sulama öncesi klorofil değerleri (SPAD-502)

\begin{tabular}{ccccccc}
\hline Tarih & $\mathrm{S}_{0}$ & $\mathrm{~S}_{50}$ & $\mathrm{~S}_{75}$ & $\mathrm{~S}_{100}$ & CV(\%) & LSD \\
\hline 18-Tem & $47.8 \mathrm{a}$ & $41.6 \mathrm{~b}$ & $39.1 \mathrm{bc}$ & $36.1 \mathrm{c}$ & 5.28 & 3.47 \\
23-Tem & $48.3 \mathrm{a}$ & $40 \mathrm{~b}$ & $35.4 \mathrm{~b}$ & $38.7 \mathrm{~b}$ & 8.45 & 5.49 \\
28-Tem & $46.5 \mathrm{a}$ & $42.9 \mathrm{ab}$ & $35.4 \mathrm{c}$ & $39.1 \mathrm{bc}$ & 6.19 & 4.06 \\
02-Ağu & $49.7 \mathrm{a}$ & $44.7 \mathrm{ab}$ & $38.3 \mathrm{c}$ & $40.7 \mathrm{bc}$ & 8.32 & 5.77 \\
08-Ağu & $49.8 \mathrm{a}$ & $43.9 \mathrm{~b}$ & $39.4 \mathrm{c}$ & $41.4 \mathrm{bc}$ & 5.79 & 4.04 \\
13-Ağu & $47 \mathrm{a}$ & $47 \mathrm{a}$ & $41.2 \mathrm{a}$ & $43.5 \mathrm{a}$ & 8.69 & 6.21 \\
18-Ağu & $53.1 \mathrm{a}$ & $40.4 \mathrm{~b}$ & $36.9 \mathrm{~b}$ & $38.2 \mathrm{~b}$ & 7.17 & 4.83 \\
23-Ağu & $46.9 \mathrm{a}$ & $42.1 \mathrm{a}$ & $41.6 \mathrm{a}$ & $43.1 \mathrm{a}$ & 11.9 & 7.77 \\
Ortalama & 46.9 & 43 & 38.3 & 40.7 & & \\
\hline
\end{tabular}

Çizelge 5. Sulama sonrası klorofil değerleri (SPAD-502)

\begin{tabular}{ccccccc}
\hline Tarih & $\mathrm{S}_{0}$ & $\mathrm{~S}_{50}$ & $\mathrm{~S}_{75}$ & $\mathrm{~S}_{100}$ & CV(\%) & LSD \\
\hline 25-Tem & $49.9 \mathrm{a}$ & $40.6 \mathrm{~b}$ & $37.8 \mathrm{~b}$ & $38.5 \mathrm{~b}$ & 6.68 & 4.46 \\
30-Tem & $48.2 \mathrm{a}$ & $44.3 \mathrm{bc}$ & $39.5 \mathrm{bc}$ & $38.4 \mathrm{c}$ & 8.31 & 5.66 \\
04-Ağu & $47.8 \mathrm{a}$ & $42.6 \mathrm{bc}$ & $37.1 \mathrm{bc}$ & $40.4 \mathrm{c}$ & 6.54 & 4.39 \\
10-Ağu & $49.9 \mathrm{a}$ & $42.5 \mathrm{bc}$ & $37.6 \mathrm{bc}$ & $40.4 \mathrm{c}$ & 5.86 & 4 \\
15-Ağu & $51.2 \mathrm{a}$ & $41.7 \mathrm{~b}$ & $41 \mathrm{~b}$ & $43.9 \mathrm{~b}$ & 9.11 & 6.48 \\
20-Ağu & $49.6 \mathrm{a}$ & $44.1 \mathrm{~b}$ & $40.3 \mathrm{~b}$ & $41.8 \mathrm{~b}$ & 7.7 & 5.41 \\
25-Ağu & $50.1 \mathrm{a}$ & $42.6 \mathrm{~b}$ & $38.9 \mathrm{bc}$ & $39.3 \mathrm{c}$ & 7.14 & 4.86 \\
Ortalama & 46.6 & 40.3 & 36.8 & 38.4 & & \\
\hline
\end{tabular}

Konulara göre sulama öncesi yapılan klorofil ölçüm değerlerinde topraktaki nemin azalmasından dolayı değerlerin yüksek çıktığı belirlenmiştir. S100 konusunda 31.8-43.5; $\mathrm{S}_{75}$ konusunda 35.4-41.6; $\mathrm{S}_{50}$ konusunda 40-47; $\mathrm{S}_{0}$ konusunda 45.5-53.1 arasinda değiştiği gözlemlenmiştir. Bu sonuçlara göre konulara verilen su miktarı azalması ile birim yaprak alanındaki klorofil miktarında artış olmuştur.

Sulama sonrası klorofil değerleri Duncan siniflandirmasina göre uygulanan sulama suyu miktarına bağlı olarak azalmalar olmuştur (Çizelge 5). $\mathrm{S}_{100}$ konusunda 35.2-43.9; $\mathrm{S}_{75}$ konusunda 36.1-41; $\mathrm{S}_{50}$ konusunda 40.6-44.3; $\quad \mathrm{S}_{0}$ konusunda $48.2-51.2$ arasında değiştiği gözlemlendi. Sulama sonrası alınan klorofil okumalarında sulama öncesine göre düşüşler görülmüştür. $\mathrm{Bu}$ sonuçlara göre sulama yapılması klorofil değerlerinde düşüler görülmesine neden olmuştur.

Bitki dokularının hızlı gelişmesi daha fazla su almasına neden olurken klorofil miktarında azalma olmaktadır (Kaçar ve ark., 2006). Dolayısıyla Çizelge 4 ve 5 'de azalan sulama miktarı ile pamuk bitkisinin yapraktaki klorofil içeriklerinin önemli düzeyde arttığını S $\mathrm{S}_{100} \quad$ (tam sulama) konusunda klorofil miktarın $\mathrm{S}_{0}$ (sulamasız) konusuna göre az olduğu belirlenmiştir.

Ekinci ve ark. (2008) pamukta yaptıkları çalışmada yaprak klorofil değerinin 48.55-50.54 arasında 
olduğunu, pamuk çeşitlerinde en yüksek ve en düşük değerin normal yapraklı çeşitlerde olduğunu söylemişlerdir.

Çakaloğulları (2015) Bornova koşullarında yaptığı bazı pamuk çeşitlerinin tarla koşullarında su kullanım etkinliği çalışmasında en yüksek ortalama SPAD değerlerini MAY P 06 (45.0) ve ST 468 (44.4), en düşük
SPAD değerini ise ARCOT 009 (41.7) çeşidinin elde etmiştir.

Klorofil Değeri (SPAD) - Bitki Su Tüketim (ET) İlişkisi Denemede sulama konularına göre ortalama klorofil değeri (Duncan gruplama) ve bitki su tüketimi arasındaki ilişkiler Çizelge 6 ve Şekil 5’de verilmiştir.

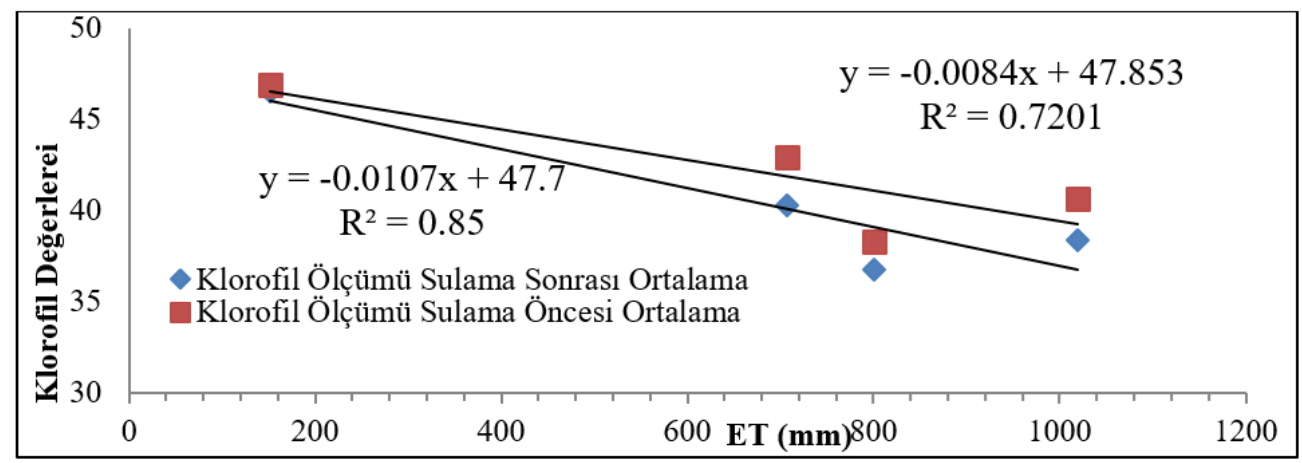

Şekil 5. Klorofil değeri-bitki su tüketim ilişkisi

Cizelge 6. Klorofil değeri-bitki su tüketim Duncan gruplama ilişkisi

\begin{tabular}{cccc}
\hline Sulama & ET & Klorofil Değeri (SPAD) & Klorofil Değeri (SPAD) \\
Konuları & $(\mathrm{mm})$ & Sulama Öncesi Ortalama & Sulama Sonrasi Ortalama \\
\hline $\mathrm{S}_{100}$ & 1018.98 & $40.7 \mathrm{c}$ & $38.4 \mathrm{c}$ \\
$\mathrm{S}_{75}$ & 800.77 & $38.3 \mathrm{~d}$ & $36.8 \mathrm{~d}$ \\
$\mathrm{~S}_{50}$ & 707.04 & $43 \mathrm{~b}$ & $40.3 \mathrm{~b}$ \\
$\mathrm{~S}_{0}$ & 151.06 & $46.9 \mathrm{a}$ & $46.6 \mathrm{a}$ \\
\hline
\end{tabular}

Deneme konuları ele alındığında yaprak su potansiyeli ile bitki su tüketimi arasında doğrusal ilişkiler belirlenmiştir. Alınan değerlere ilişkin denklemler sulama öncesi $-0.0084 x+47.853\left(R^{2}=0.7201\right)$, sulama sonrası y $=-0.0107 \mathrm{x}+47.7\left(\mathrm{R}^{2}=0.85\right)$ bulunmuştur.

Çizelge 6'da görüldüğü gibi sulama öncesi ve sonrası klorofil değerleri ortalama en yüksek değer $\mathrm{S}_{0}$ konusunda görülürken en düşük $\mathrm{S}_{75}$ konusunda görülmüştür. Bitkide su tüketimi artığında klorofil değerinde genel olarak azalma görülmüştür. Buna göre bitkinin su stresine girmesi klorofil değerinde artış olmasına neden olmaktadır.

\section{Klorofil Değeri (SPAD) - Yaprak Su Potansiyeli (YSP)} İlişkisi

Denemede sulama konularına göre ortalama klorofil değeri ve yaprak su potansiyeli (YSP) (Duncan gruplama) arasındaki ilişkiler Çizelge 7'de verilmiştir.

Çizelge 7'de görüldüğü gibi ortalama klorofil ve yaprak su potansiyeli ölçümleri sulama konularına göre farklılıklar göstermektedir. Alınan ortalama değerlerinde hem sulama öncesi hem de sulama sonrası klorofilin pozitif yönde ve yaprak su potansiyelinin negatif yönde en düşük $S_{75}$ konusundayken en yüksek $\mathrm{S}_{0}$ konusunda görülmüştür. Sulamaya göre klorofil ve yaprak su potansiyeli zit yönde çıkmıştır. Sulama miktarı azaldıkça klorofil değerinin pozitif yönde yükseldiğini ve yaprak su potansiyelinde negatif yönde artığ̣ görülmüştür. $\mathrm{Bu}$ sonuçlara göre yaprak su potansiyelinin ve klorofil değerinin su stresinde ayırt etmede ve sulama programında kullanılabileceği söylenebilir.

Çizelge 7. Klorofil değeri - yaprak su potansiyeli Duncan gruplama ilişkisi

\begin{tabular}{ccccc}
\hline $\begin{array}{c}\text { Sulama } \\
\text { Konuları }\end{array}$ & $\begin{array}{c}\text { Klorofil Değeri } \\
\text { (SPAD) Sulama } \\
\text { Oncesi Ortalama }\end{array}$ & $\begin{array}{c}\text { Klorofil Değeri } \\
\text { (SPAD) Sulama } \\
\text { Sonrası Ortalama }\end{array}$ & $\begin{array}{c}\text { YSP Sulama } \\
\text { Öncesi } \\
\text { Ortalama }\end{array}$ & $\begin{array}{c}\text { YSP Sulama } \\
\text { Sonrası } \\
\text { Ortalama }\end{array}$ \\
\hline $\mathrm{S}_{100}$ & $40.7 \mathrm{c}$ & $38.4 \mathrm{c}$ & $-25 \mathrm{~b}$ & $-22.7 \mathrm{~b}$ \\
$\mathrm{~S}_{75}$ & $38.3 \mathrm{~d}$ & $36.8 \mathrm{~d}$ & $-24.4 \mathrm{a}$ & $-21 \mathrm{a}$ \\
$\mathrm{S}_{50}$ & $43 \mathrm{~b}$ & $40.3 \mathrm{~b}$ & $-28.1 \mathrm{c}$ & $-26 \mathrm{c}$ \\
$\mathrm{S}_{0}$ & $46.9 \mathrm{a}$ & $46.6 \mathrm{a}$ & $-36.6 \mathrm{~d}$ & $-31.8 \mathrm{~d}$ \\
\hline
\end{tabular}




\section{SONUÇ}

Çalışma, 2016 yılında Kahramanmaraş ili Doğu Akdeniz Geçit Kuşağ alanında yürütülmüş̧ür. $\mathrm{Bu}$ çalışmada, Kahramanmaraş koşullarında Stoneville 468 pamuk bitkisinin farkl sulama seviyelerinde yaprak su potansiyeli ve klorofil değerini belirlemek amacıyla yapılmıştır.

Araştırmada, damla sulama yöntemi ile tam sulama $\left(\mathrm{S}_{100}\right), \mathrm{S}_{100}$ 'de verilen suyun \%25 eksiği kadar sulama suyu uygulaması $\mathrm{S}_{75}, \mathrm{~S}_{100}$ 'de verilen suyun \%50 eksiği kadar sulama suyu uygulamasi $\mathbf{S}_{50}$ ve sulamasiz $\mathbf{S}_{0}$ olmak üzere 4 farklı sulama uygulaması 3 tekerrür altında gerçekleştirilmiştir. Büyüme mevsimi boyunca konulara verilen su miktarları $\mathrm{S}_{100}$ konusunda 887 $\mathrm{mm}, \mathrm{S}_{75}$ konusunda $654 \mathrm{~mm}$ ve $\mathrm{S}_{50}$ konusunda $533 \mathrm{~mm}$ sulama suyu uygulanmıştır. $\mathrm{S}_{0}$ (sulamasız) kısma yağışlar haricinde sulama suyu verilmedi. Çalışmada pamuk bitkisinin mevsimlik su tüketimi $\mathbf{S}_{100}$ konusunda $1019 \mathrm{~mm}, \mathrm{~S}_{75}$ konusunda $801 \mathrm{~mm}, \mathrm{~S}_{50}$ konusunda $707 \mathrm{~mm}$ ve $\mathrm{S}_{0}$ konusunda $151 \mathrm{~mm}$ olarak hesaplanmıştır.

Yaprak su potansiyeli sulama konulara göre sulama öncesi ve sonrası alınan değerlere gün ortası ölçülmüştür. Sulama öncesi ve sonrası alınan değerlere göre negatif yönde en yüksek değer $\mathrm{S}_{0}$ konusunda, negatif yönde en düşük değer $\mathrm{S}_{100}$ konusunda belirlenmiştir. Sonuç olarak, ölçümler tam sulamada $\left(\mathrm{S}_{100}\right)-23.4$ ile -26.91 bar, $\mathrm{S}_{100}$ 'de verilen suyun \%25 eksiği kadar sulama suyu uygulaması $\mathrm{S}_{75}$ 'de -22.74 ile -26.1 bar, S100'de verilen suyun \%50 eksiği kadar sulama suyu uygulaması S50'de $^{2} 26.6$ ile -31.08 bar ve sulamasız koşul So'da -33.08 ile -41.24 bara ulaştığında sulamaların yapılabileceği anlaşılmıştır. Yaprak su potansiyelinin bitki su tüketimine göre ise zit yönlü çıkmıştır. Bitki su tüketim değeri azaldıkça yaprak su potansiyeli değerinde negatif yönde artmaya başlamıştır. Alınan sonuçlara göre sulamalar yaprak su potansiyeli (YSP) değerlerine göre planlanabileceği anlaşılmıştır.

Yaprak klorofil içeriği $\mathrm{S}_{100}$ (Tam sulama), $\mathrm{S}_{75}, \mathrm{~S}_{50}$ ve $\mathrm{S}_{0}$ (sulamasız) konularda sulama öncesi ve sonrası SPAD değerleri alınmıştır. Sulama öncesi alınan değerler sulama sonrası alınan değerlerden yüksek çıkmıştır. Sonuç olarak, sulama öncesi klorofil içeriğinin ortalama (SPAD) 46.9-38.3 arasında olduğu zaman sulamanın yapılacağı anlaşılmıştır. Pamuğu su stresine girmesi klorofil değerinde artış olmasına neden olmuştur. Klorofil değerlerinin su stresini ayırt etmede kullanıla bileceği görülmüştür.

\section{TEŞEKKÜR}

$\mathrm{Bu}$ araştırma bir yüksek lisans çalışmasının sonuçlarını içermektedir. Araştırma Kahramanmaraş Sütçü İmam Üniversitesi Bilimsel Araştırma Projeleri Birimi tarafından desteklenmiştir. Verdikleri destek için KSÜ BAP birimine ve Doğu Akdeniz Geçit Kuşağı Araştırma Enstitüsüne teşekkür deriz.

\section{KAYNAKLAR}

Argyrokastritisa IG, Papastylianoub PT, Alexandrisa S 2015. Leaf Water Potential and Crop Water Stress Index Variation for full and Deficit Irrigated Cotton in Mediterranean Conditions. Agriculture and Agricultural Science Procedia 4:463-470.

Baştuğ R, Kanber, R 1989. Sulama Programının Geliştirilmesinde Bitkilerin İçsel Su Durumlarını Belirleyen yöntemlerden Yararlanma Olanakları. Akdeniz Üniversitesi, Ziraat Fakültesi Dergisi, $2(1): 17-30$

Burke JJ, Mahony JO 2001. Protective Role in Acquired Thermotolerance of Developmentally Regulated Heat Shock Proteins in Cotton Seeds. The Journal of Cotton Sci. 5:174-183.

Çakaloğulları U 2015. Bazı Pamuk Çeşitlerinin Tarla Koşullarında $\mathrm{Su}$ Kullanım Etkinliklerinin Belirlenmesi ve İlişkisi Fizyolojik Parametrelerin İncelenmesi. Ege Üniversitesi Fen Bilimleri Enstitüsü, Yüksek Lisans Tezi, 47 sayfa, Bornovaİzmir.

Çolak YB, Yazar A 2012. Akdeniz Bölgesi Flame Seedless ve Italia Sofralık Üzüm Çeşitlerinde Yaprak Su Potansiyeline Sulama Programlarının Geliştirilmesi. Çukurova Üniversitesi Fen ve Mühendislik Bilimleri Dergisi 28(4) : 163-173.

Ekinci R, Gencer O, Başbağ S 2008. Okra ve Normal Yapraklı Pamuklarda (Gossypium hirsutum L.) Bazı Fizyo-Morfolojik Oluşumların Verim ile Olan İlişkileri. Tarım Bilimleri Dergisi 2008, 14 (3) 217221.

Ertek A, Kanber R 2001. Damla Sulama Yöntemiyle Uygulanan Farklı Sulama Programlarmın Bitki Gelişmesine Etkisi. Turk J Agric For, 25 : 415-425.

Fischer RA 2001. Selection Traits for Improving Yield Potential. Application of Physiology in Wheat Breeding, Chapt-13, p.148-159.

Güreli R, Mert M 2016. Bazı Pamuk Genotiplerinin, Diyarbakır Koşullarında, Erkencilik, Verimlilik ve Lif Teknolojik Özellikleri Yönünden Değerlendirilmesi. Mustafa Kemal Üniversitesi Ziraat Fakültesi Dergisi, 21(1):1-11.

Hisio TC 1993. Plant Atmosphere Interactions, Evapotranspration and Irrigation Scheduling Course I.C.M.A.S. Bari, Italy, 148s.

Judith GC, Kenji O 1990. Chlorophyll a Fluorescence and Carbon Assimilation in Developing Leaves of Light-Grown Cucumber, Plant Physiol, 93: 10781082.

Kaçar B, Katkat AV, Öztürk Ş 2006. Bitki Fizyolojisi. Nobel Yayınları, 2. Baskı, Ankara, 563s.

Karademir Ç, Karademir E, Ekinci R, Gençer O 2009. Correlations and Pathco Efficient Analysis Between Leaf Chlorophyll Content, Yield and Yield Components in Cotton (Gossypium hirsutum L.) 
Under Drought Stress Conditions, Agrobotanici Cluj- Napoca, 37 (2): 241-244.

Li P, Dong H, Liu A, Liu J, Sun M, Wang G, Zhang S, Li Y, Mao S 2014. Diagnosis of Premature Senescence of Cotton Using SPAD Value, Agricultural Sciences (5), 992-999pp.

Maya F 2007. Farklı Su ve Gübre Sistemlerinde Pamuk Bitkisinde Yaprak $\mathrm{Su}$ Potansiyelinin Değişimi. Çukurova Üniversitesi Fen Bilimleri
Enstitüsü Tarımsal Yapılar ve Sulama ABD, Yüksek Lisans Tezi, 44s, Adana.

Patil MD, Biradar DP, Patil VC, Janagoudar BS 2011, Response of Cotton Genotypes to Drought Mitigation

Wanjura DF, Upchurch DR 2002. Water Status Response of Corn and Cotton to Altered Irrigation. Irrig. Sci., 21: 45-55. 